Supporting information for

A Codoped Polymeric Photocatalyst with Prolonged Carrier Lifetime and Extended Spectral Response up to $600 \mathrm{~nm}$ for Enhanced Hydrogen Evolution

Chao Wang, Weijia Wang*, Huiqing Fan*, Nan Zhao, Jiangwei Ma, Mingchang Zhang, Arun Kumar Yadav

State Key Laboratory of Solidification Processing, School of Materials Science and Engineering, Northwestern Polytechnical University, Xi'an 710072, China

* Corresponding author, tel.: +86-29-88494463, E-mail: weijia.wang@nwpu.edu.cn (W. Wang), hqfan@nwpu.edu.cn (H. Fan) 


\section{Characterization of catalyst}

The lattice structure of the as-prepared photocatalysts was characterized using an X-ray diffractometer (XRD, 7000, Shimadzu, Kyoto, Japan). The chemical structure was measured by Fourier-transform infrared spectroscopy (FTIR, TENSOR27, Bruker, Billerica, MA, USA). Surface morphologies were observed by a scanning electron microscope (SEM, JSM-6701F, JEOL, Tokyo, Japan) and transmission electron microscope (TEM, Talos F200X, FEI, Hillsborough, USA). The chemical states were analyzed by an X-ray photoelectron spectroscopy (XPS, Axis Supra, Kratos, Manchester, UK). UV-vis diffuse reflection spectroscopy of the photocatalysts was tested using a spectrophotometer (UV3150, Shimadzu, Kyoto, Japan). The fluorescence emission spectra and time-resolved fluorescence decay spectra were recorded with a fluorescence spectrophotometer (FLS980, Edinburgh Instruments, Edinburgh, Britain). Incident photon conversion efficiency (IPCE, PL-SPS, Perfect Light, Beijing, China) was carried out in a surface photovoltage spectrometer. Elemental analysis was performed on an organic elemental analyzer (EA, vario EL cube, Elementar, Langenselbold, Germany). The specific surface area and porous characteristic were tested by nitrogen adsorption-desorption (BET, VSorb2800 P, Gold APP Corp., Beijing, China) at $77 \mathrm{~K}$.

\section{Electrochemical tests}

All electrochemical tests in this work were carried out using an electrochemical workstation (CHI660E, Chenhua, Shanghai, China) in a three-electrode system, where a platinum plate and $\mathrm{Ag} / \mathrm{AgCl}$ in $3 \mathrm{M} \mathrm{KCl}$ were served as counter electrode and reference electrode, respectively. The working electrode was prepared by a dip-coating method. In a typical process, $10 \mathrm{mg}$ catalyst, 6 
$\mathrm{mg}$ ethyl cellulose, $4 \mathrm{mg}$ lauric acid and $100 \mathrm{mg}$ terpineol were blended in an agate mortar to form a slurry. The slurry was then dip-coated onto a piece of indium tin oxide (ITO) conductive glass with exposed area of $0.64 \mathrm{~mm}^{2}(0.8 \mathrm{~mm} \times 0.8 \mathrm{~mm})$, which was isolated by $3 \mathrm{M}$ scotch blade. The conductive glass was then dried under an IR light for 30 min to gently evaporate solvents in the slurry. The dried electrode was heated again in a muffle furnace at $350{ }^{\circ} \mathrm{C}$ for $30 \mathrm{~min}$ at a ramping rate of $5{ }^{\circ} \mathrm{C} / \mathrm{min}$ to improve adhesion between the film and ITO. The working electrode was obtained after it is cooled down to room temperature. The three electrodes were all immersed in 0.5 $\mathrm{M} \mathrm{Na}_{2} \mathrm{SO}_{4}$ aqueous solution in the test. 


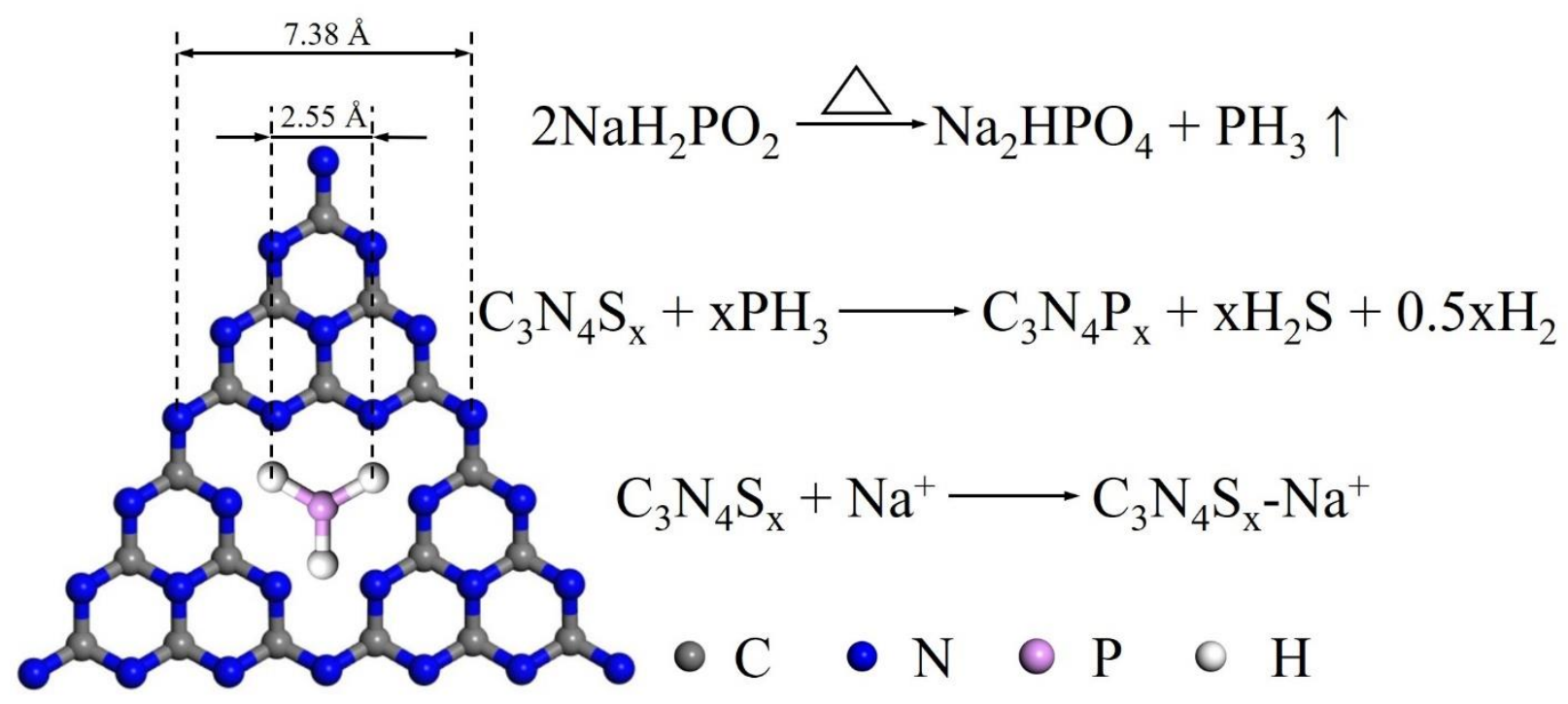

Figure S1. Schematic illustrations showing the size of cavities in $\mathrm{g}-\mathrm{C}_{3} \mathrm{~N}_{4}$ and $\mathrm{PH}_{3}$ molecules, and the main reactions during the doping process. 

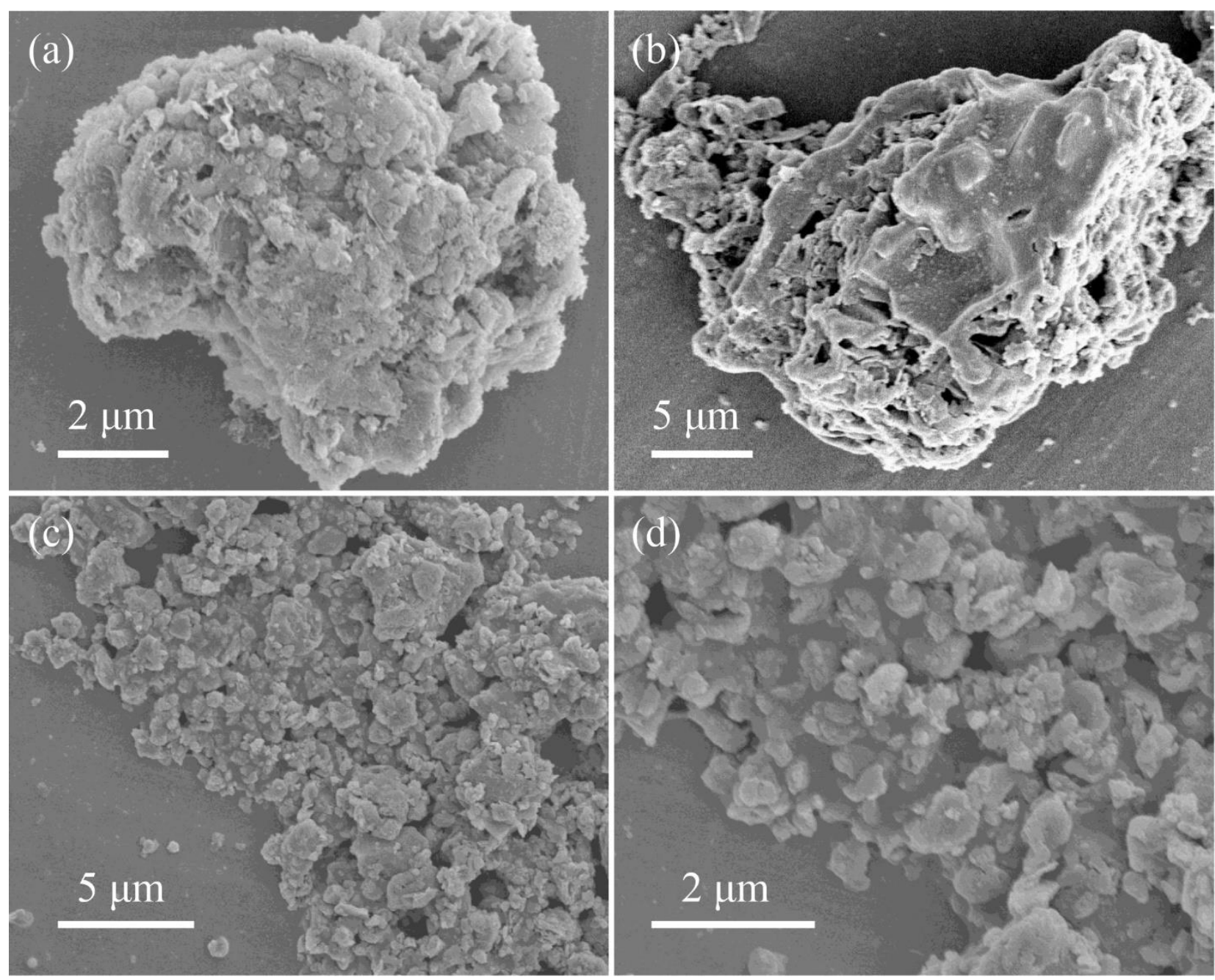

Figure S2. SEM images of (a) CN, (b) CNS and (c, d) CNP. 

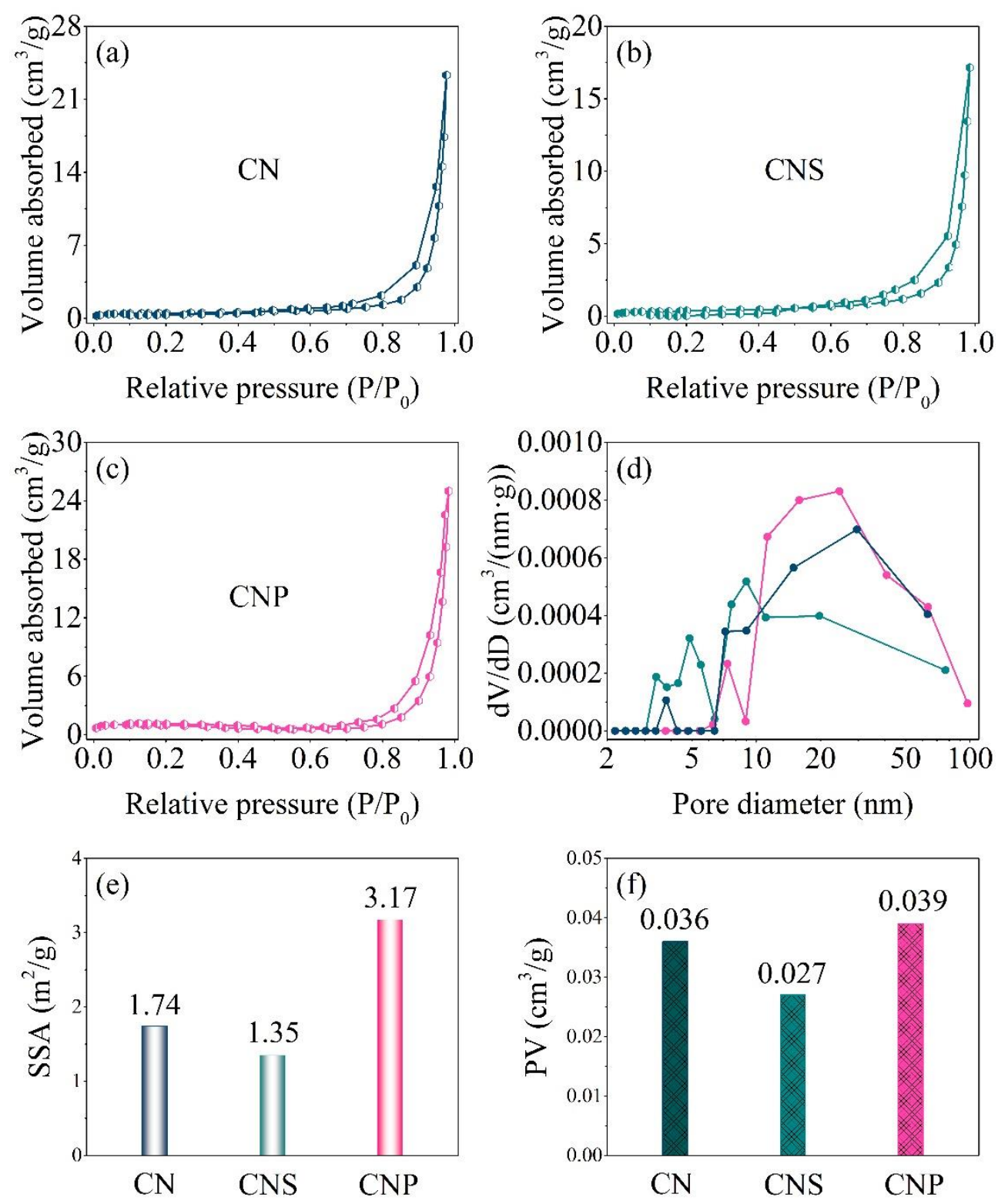

Figure S3. Nitrogen adsorption-desorption isotherms of (a) CN, (b) CNS and (c) CNP, (d) pore size distribution, (e) specific surface area and (f) total pore volume of CN, CNS and CNP. 


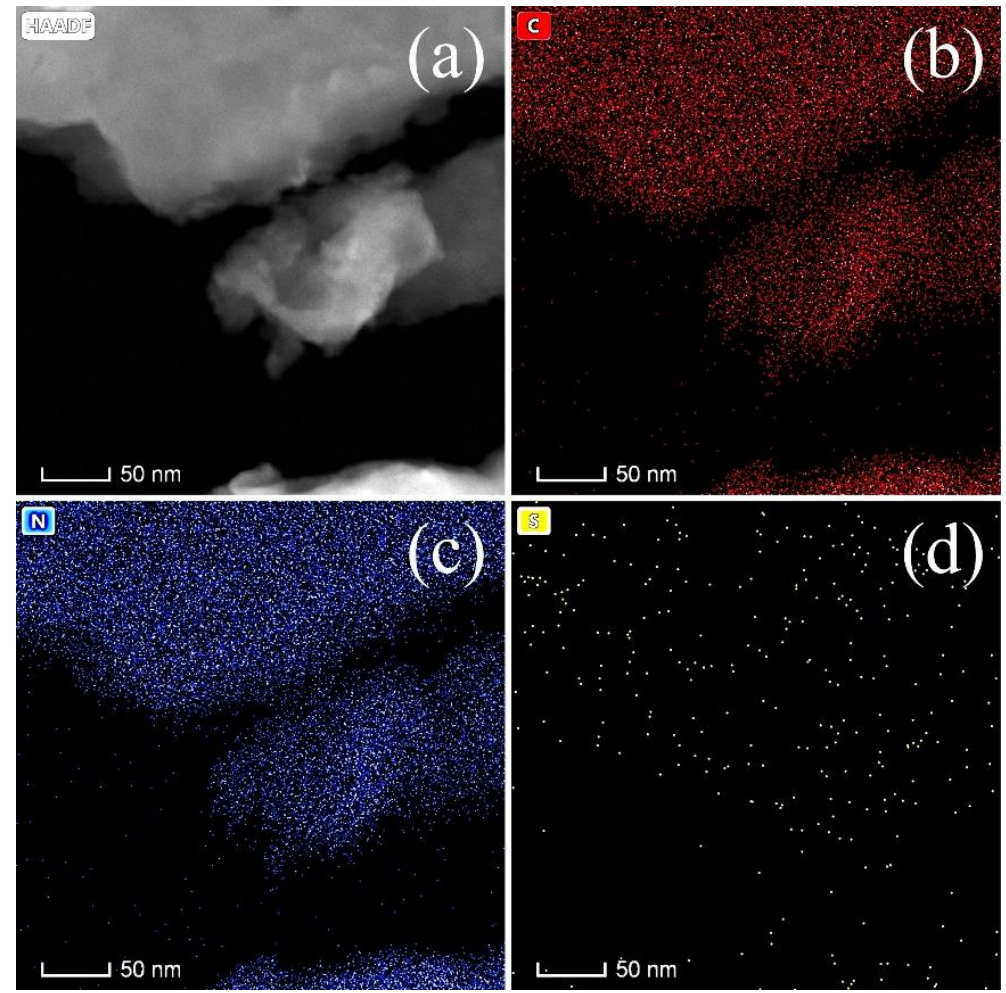

Figure S4. EDS elemental mapping of CNS, (a) HAADF image, (b) C, (c) N, and (d) S. 


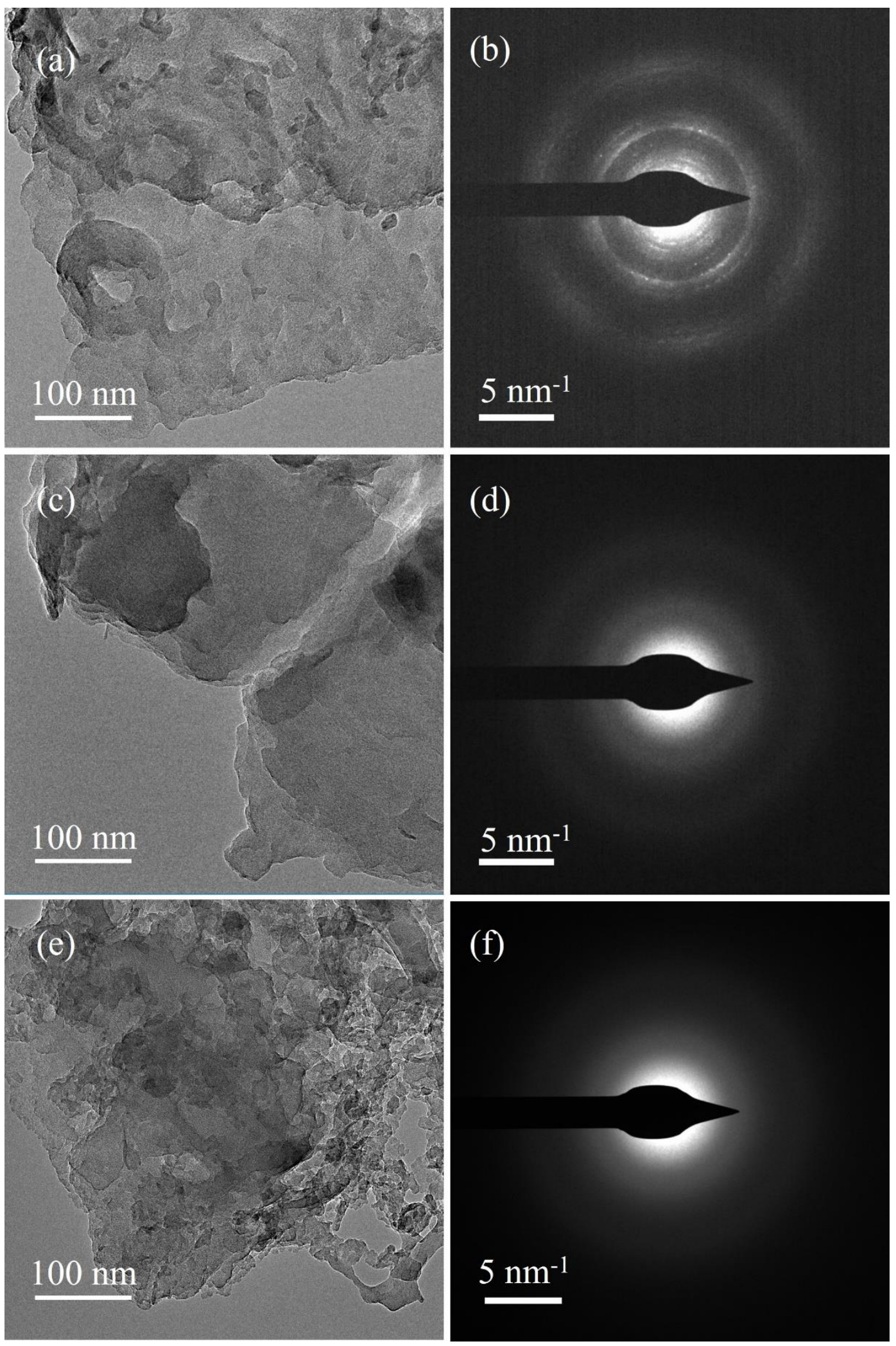

Figure S5. TEM images and SAED patterns of (a, b) CN, (c, d) CNS, and (e, f) CNP. 


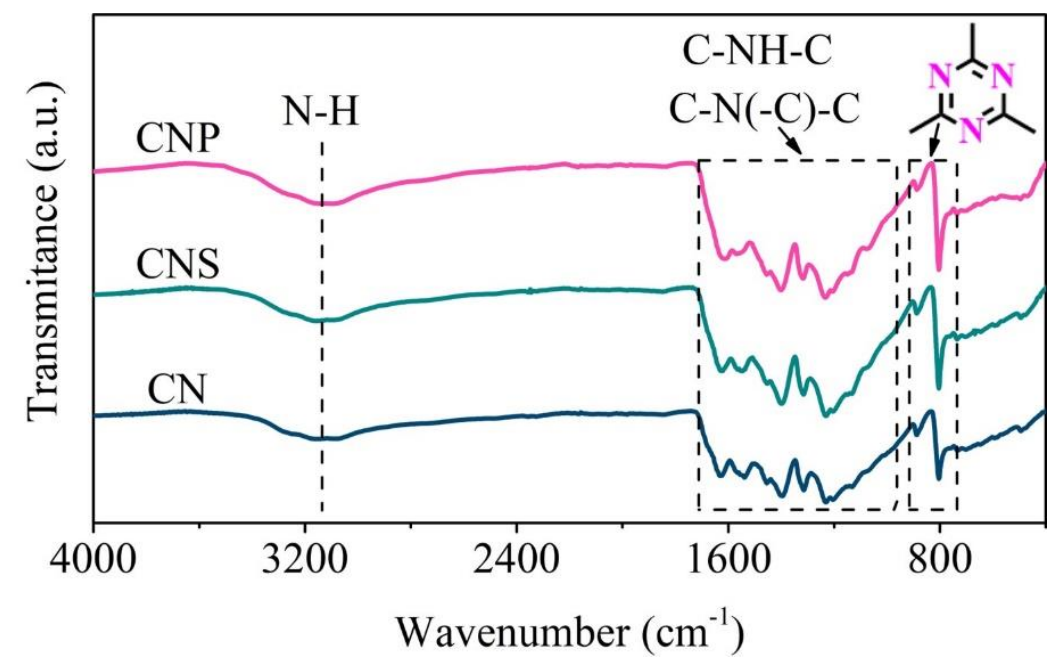

Figure S6. FTIR spectra of CN, CNS and CNP. 

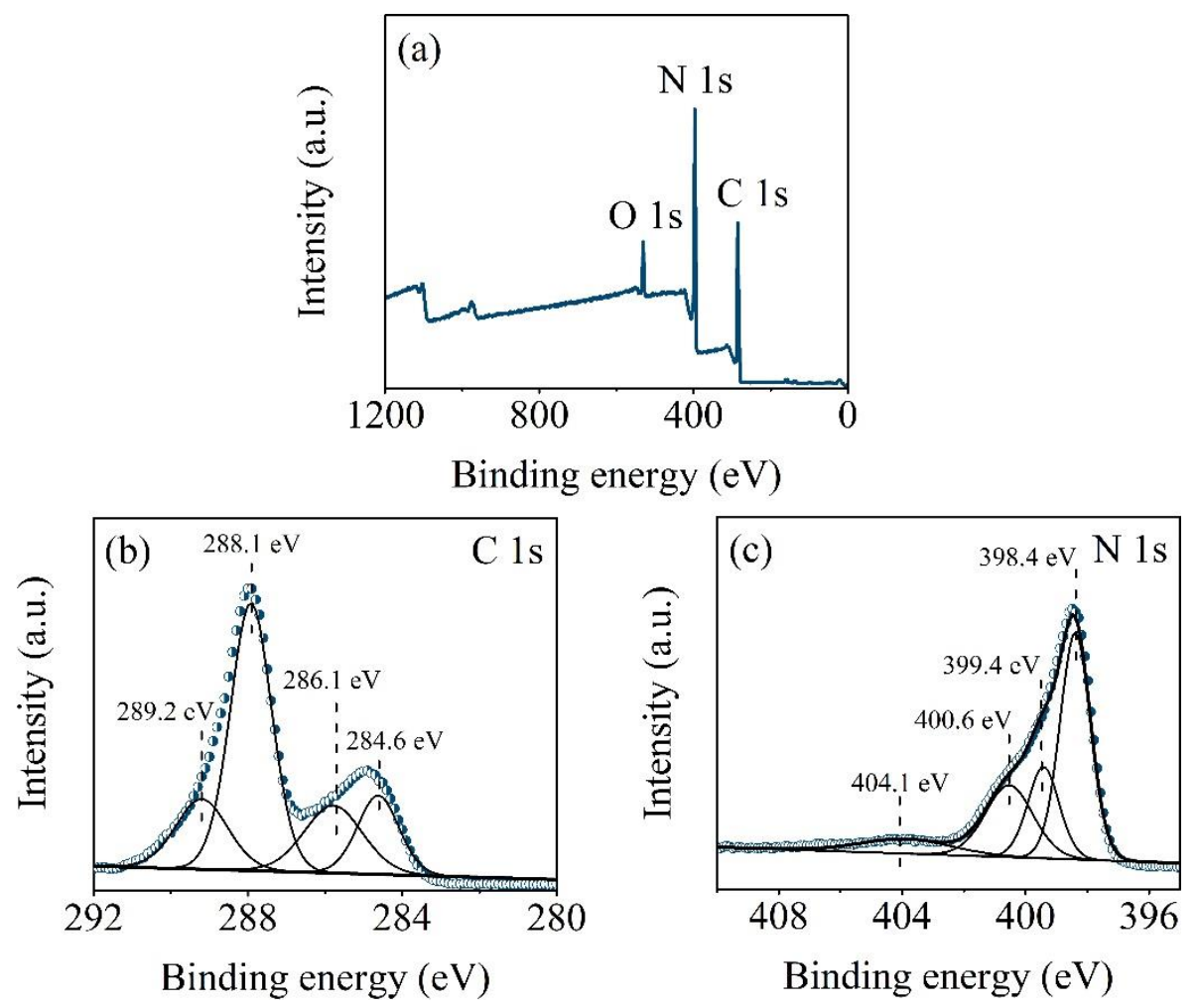

Figure S7. XPS spectra of CN, (a) survey, (b) C 1s, (c) N 1s.

Note for Figure S7: C, N and O elements are observed in the survey spectrum of CN, among which $\mathrm{O}$ is originated from the surface adsorbed $\mathrm{O}$-containing molecules, such as $\mathrm{H}_{2} \mathrm{O}$ or $\mathrm{O}_{2}$. C $1 \mathrm{~s}$ is deconvoluted into four bands. The one located at $284.6 \mathrm{eV}$ is resulted from the addictive carbon in the testing process and used for calibration. The peaks with binding energies of 286.1, 288.1 and $289.2 \mathrm{eV}$ are $\mathrm{C}$ atoms connected with linker $\mathrm{N}$ atoms, $\mathrm{N}=\mathrm{C}(-\mathrm{N})-\mathrm{N}$ structures in the heptazine units and $\mathrm{C}$ atoms linked to uncondensed amino groups, respectively. In $\mathrm{N} 1 \mathrm{~s}$ spectrum, four sub-peaks at $398.4,399.4,400.6$ and $404.1 \mathrm{eV}$ are respectively ascribed to $\mathrm{sp}^{2} \mathrm{C}=\mathrm{N}-\mathrm{C}$ structure, $\mathrm{C}-\mathrm{N}(-\mathrm{C})-\mathrm{C}$ units, amino groups and positive charge localization or the charging effects in the cyano group and hetero cycles. 

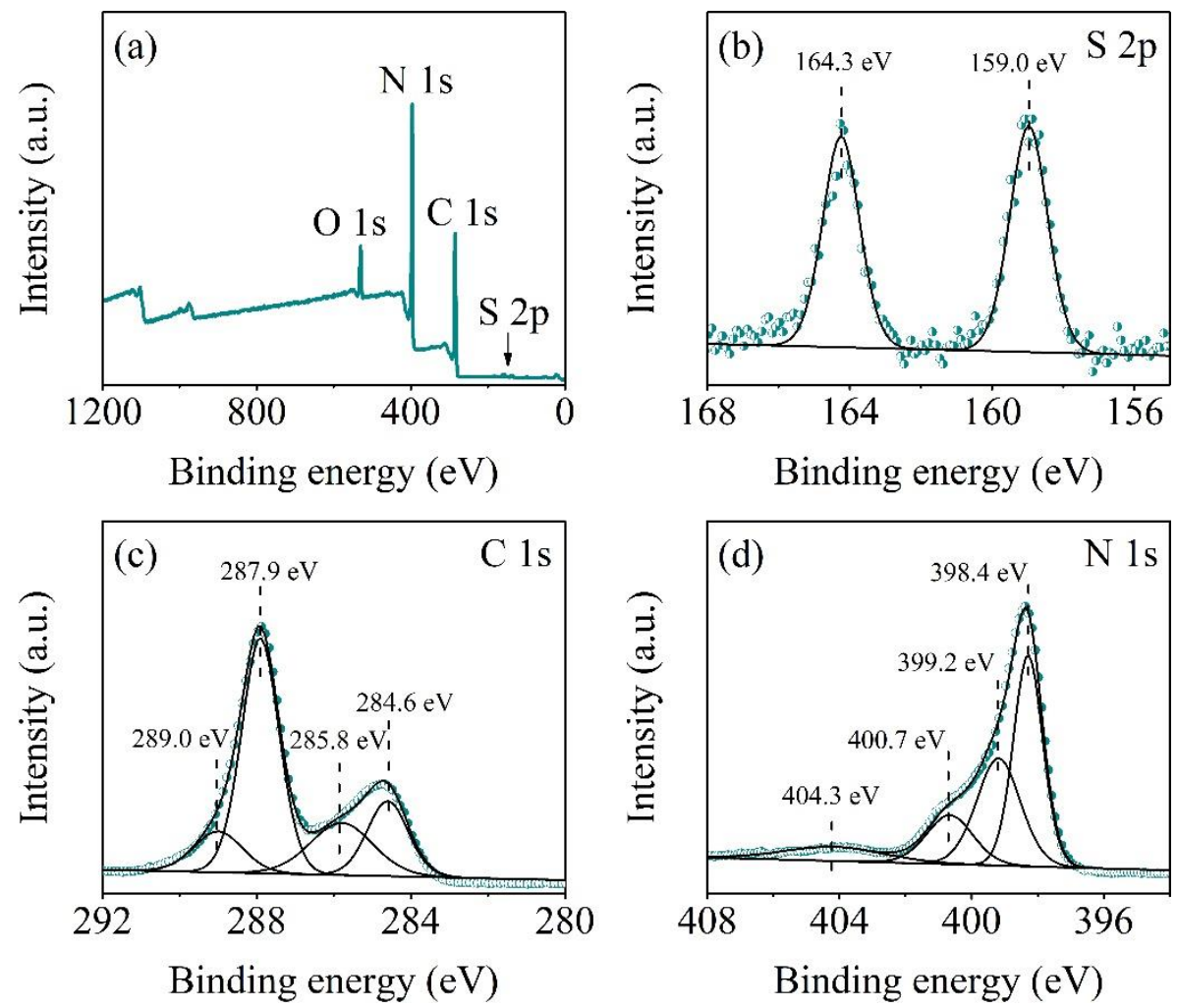

Figure S8. XPS spectra of CNS, (a) survey, (b) S 2p, (c) C 1s, and (d) N 1 s.

Note for Figure S8: Due to small doping amount, extremely weak signal of $\mathrm{S}$ is detected in the survey spectrum of CNS. However, two sub-bands located at 164.3 and $159.0 \mathrm{eV}$ are clearly noticeable in the high-resolution spectrum, which are determined to be the N-S and C-S bonds, respectively. Except for the lower percentage of $\mathrm{C}-\mathrm{NH}_{2}$ proportions compared with $\mathrm{CN}$, no other distinctions are observed in the $\mathrm{C} 1 \mathrm{~s}$ and $\mathrm{N} 1 \mathrm{~s}$ spectra of CNS. 


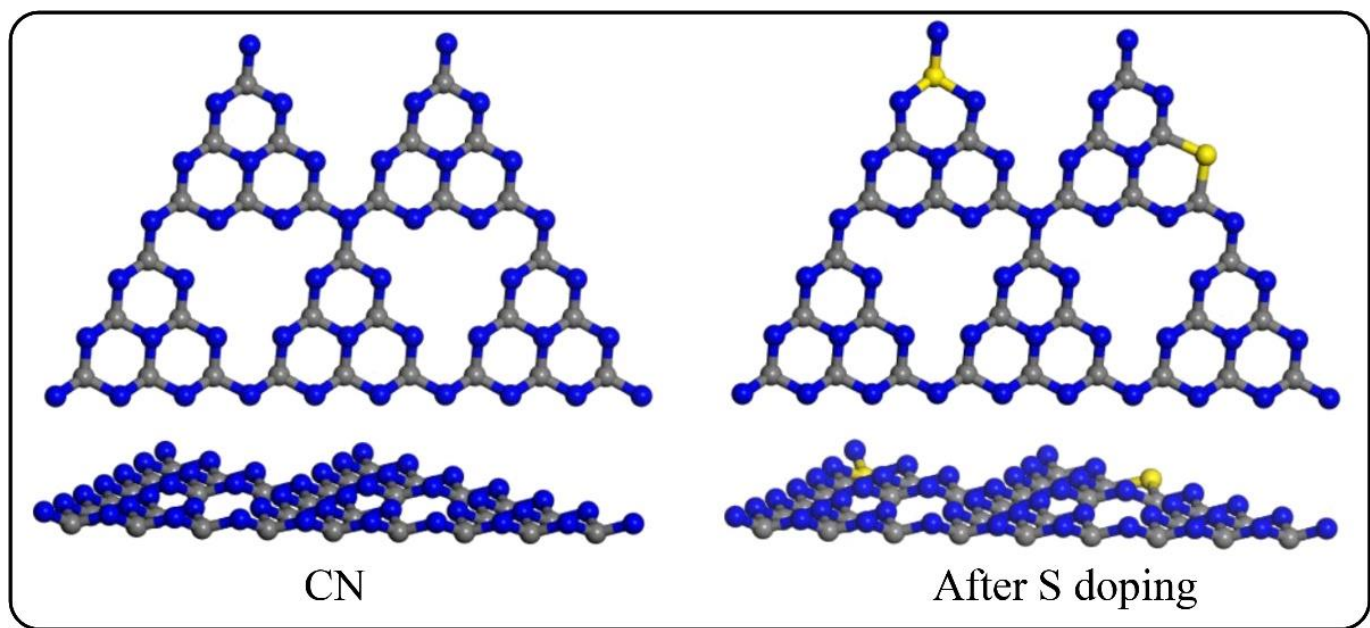

Figure S9. Doping sites of S and its effects on the lattice structure of $g-\mathrm{C}_{3} \mathrm{~N}_{4}$. 


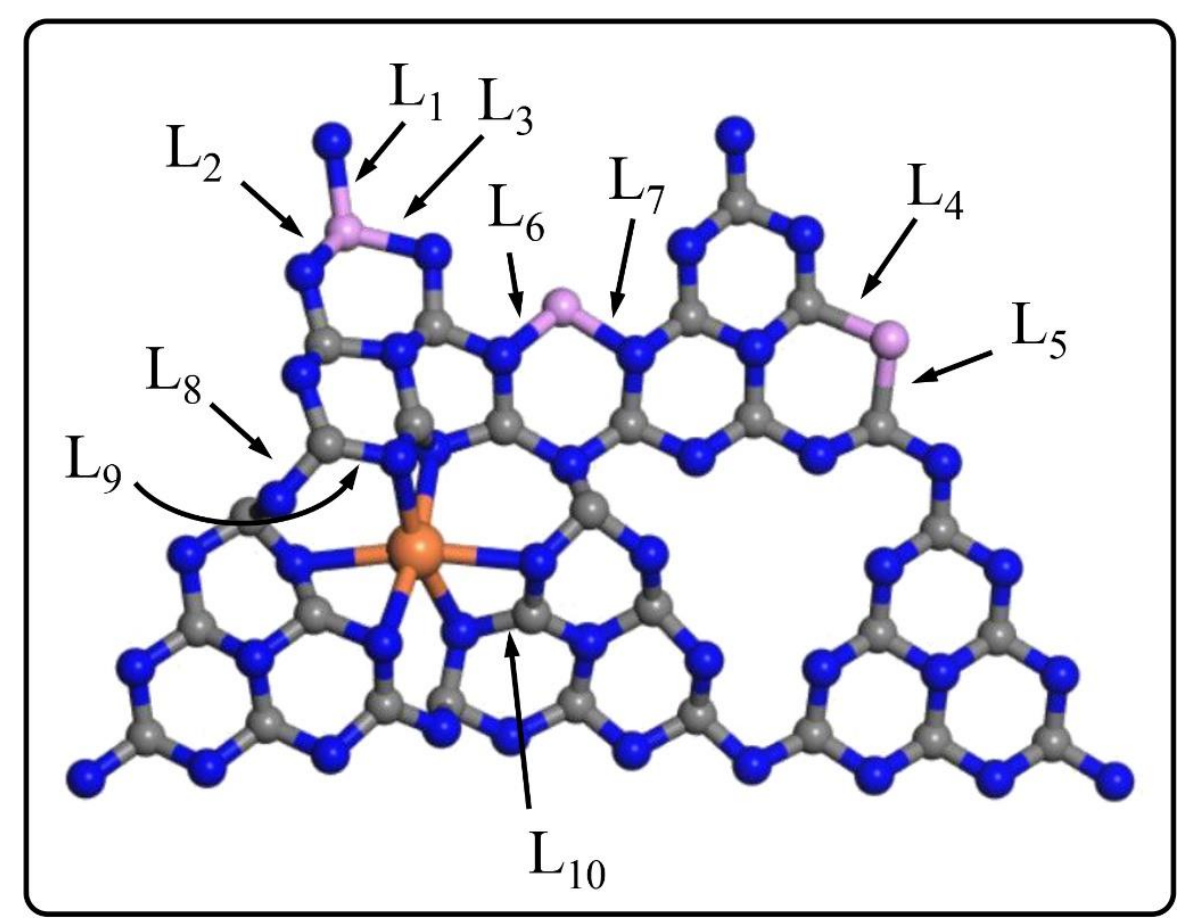

Figure S10. Some major bonds whose length may change after doping.

Table S1 Variation in the length (in the unit of $\mathrm{pm}$ ) of some major bonds before and after doping.

\begin{tabular}{ccccccccccc}
\hline & $\mathrm{L}_{1}$ & $\mathrm{~L}_{2}$ & $\mathrm{~L}_{3}$ & $\mathrm{~L}_{4}$ & $\mathrm{~L}_{5}$ & $\mathrm{~L}_{6}$ & $\mathrm{~L}_{7}$ & $\mathrm{~L}_{8}$ & $\mathrm{~L}_{9}$ & $\mathrm{~L}_{10}$ \\
\hline CN & 151 & 151 & 151 & 151 & 151 & - & - & 151 & 151 & 151 \\
After S doping & 178 & 177 & 177 & 180 & 180 & - & - & 151 & 151 & 151 \\
After P doping & 183 & 183 & 183 & 186 & 186 & 182 & 183 & 151 & 151 & 151 \\
After P-Na co-doping & 184 & 184 & 184 & 186 & 186 & 182 & 183 & 153 & 152 & 160 \\
\hline
\end{tabular}




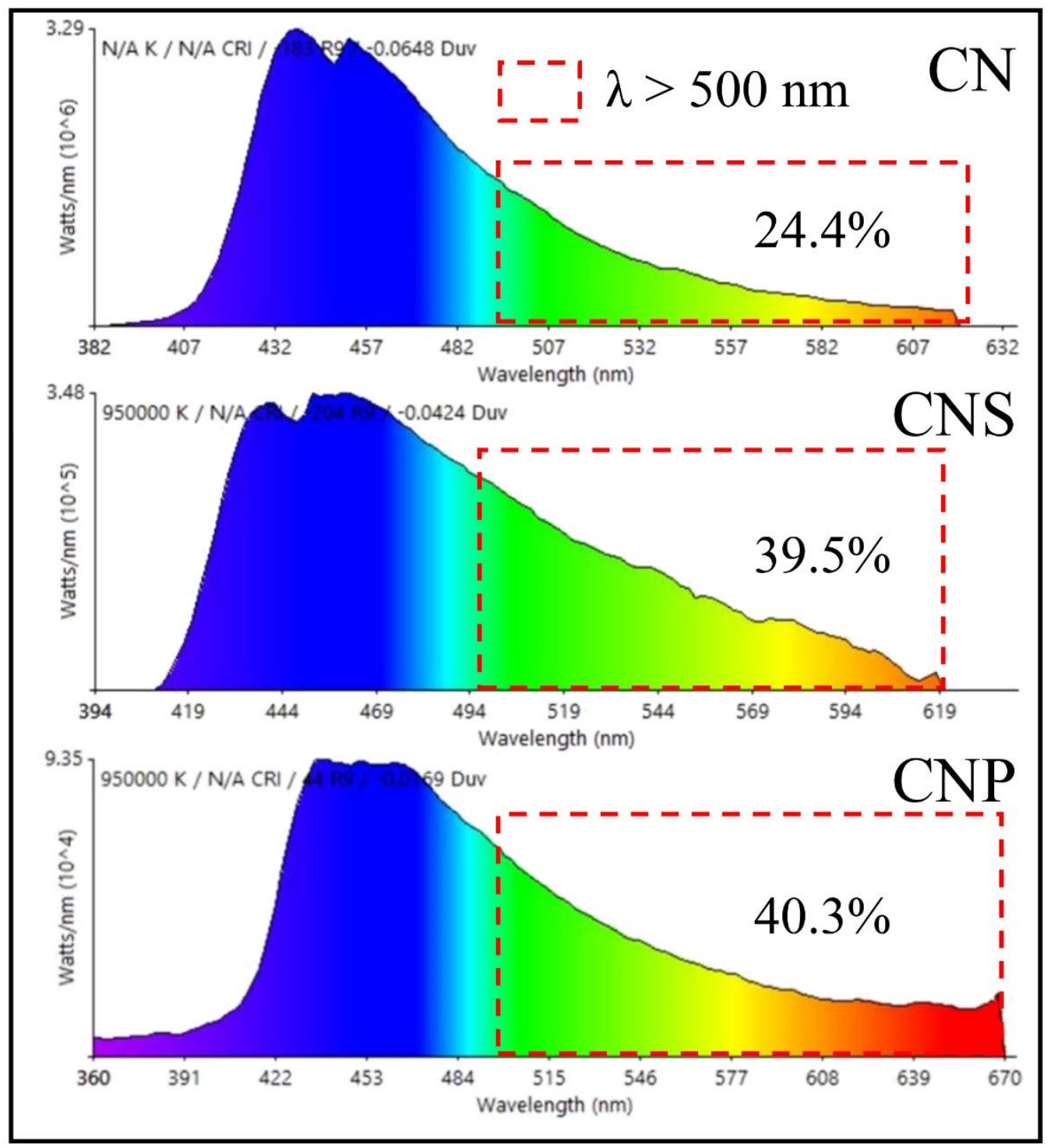

Figure S11. Steady state PL spectra of CN, CNS and CNP, the part in the red rectangle shows the percentage of emissions with wavelength longer than $500 \mathrm{~nm}$. 

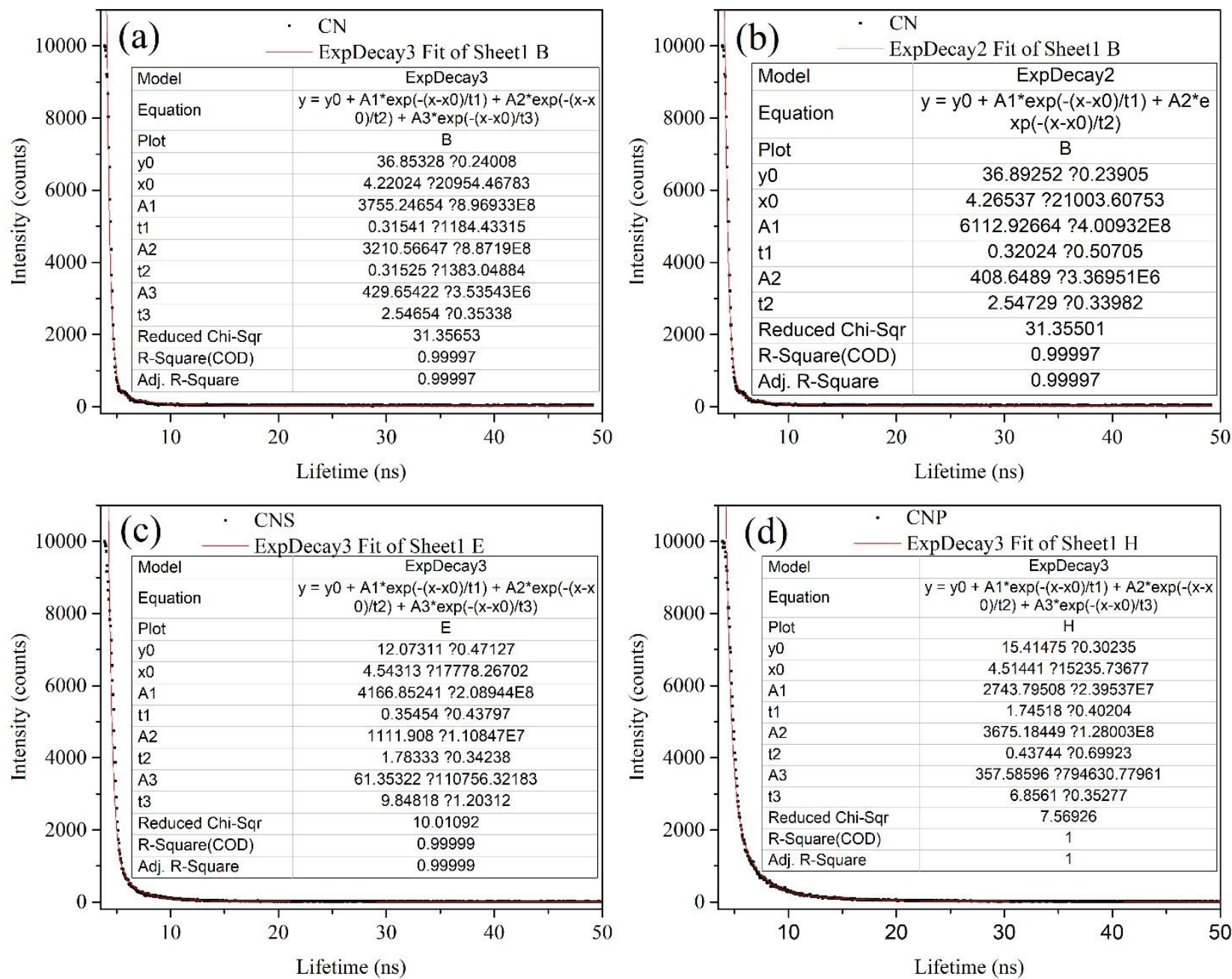

Figure S12. Fitting parameters of transient PL spectra of CN, CNS and CNP. 

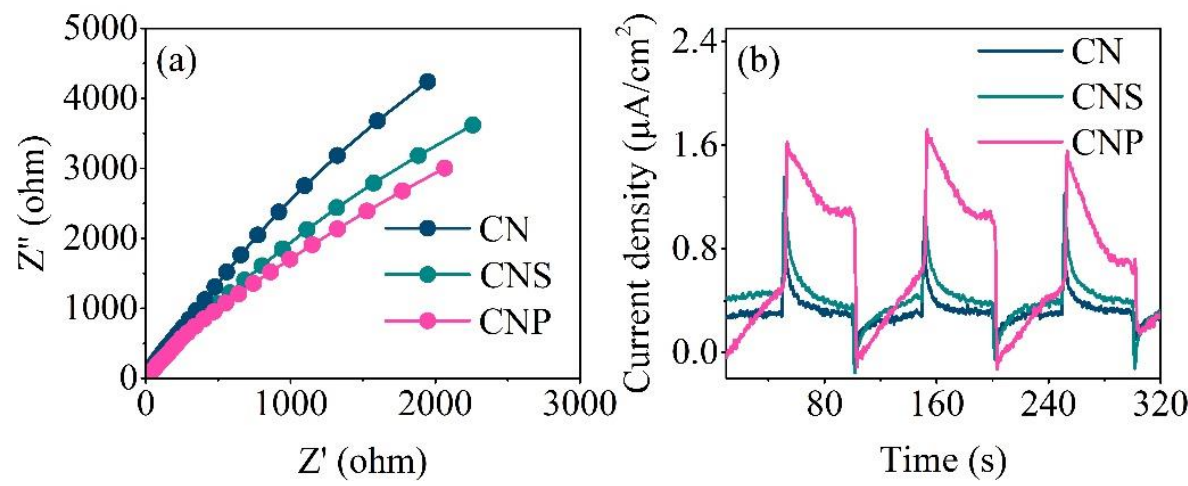

Figure S13. AC impedance spectra under visible light and transient photo-response plots of CN,

CNS and CNP.

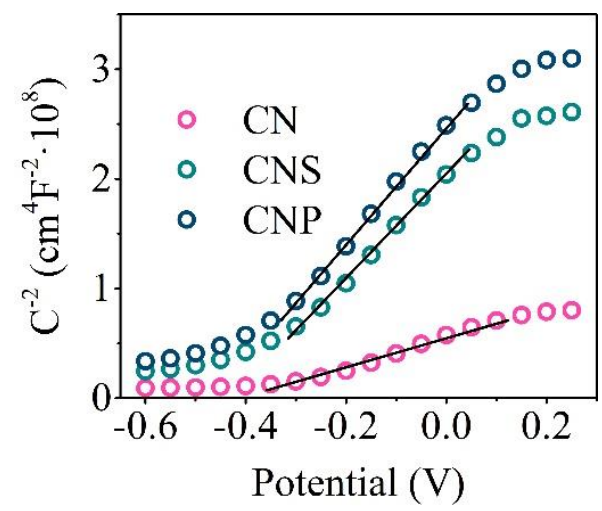

Figure S14. Mott-Schottky plots of CN, CNS and CNP. 

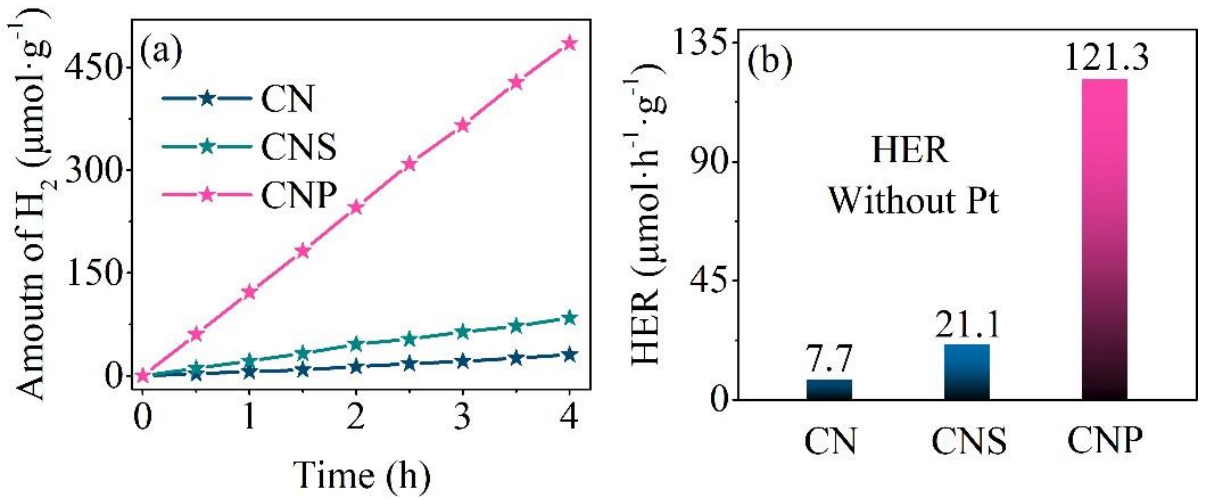

Figure S15. (a) Hydrogen evolution curves and (b) hydrogen evolution rates of CN, CNS and CNP without using Pt as co-catalysts.

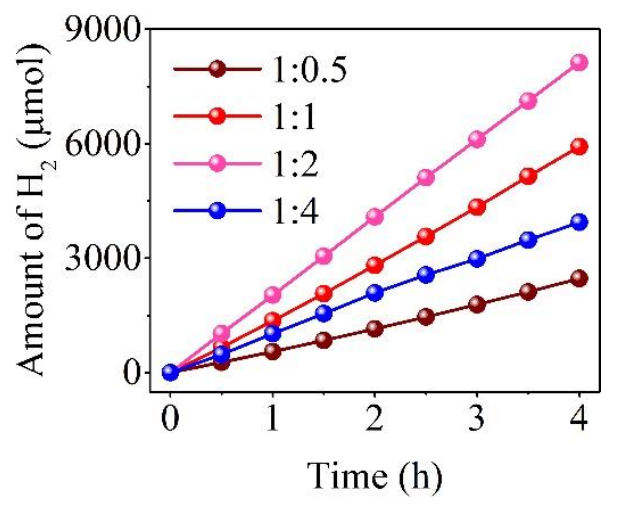

Figure S16. Hydrogen evolution curves of CNP with different ratios of $\mathrm{CNS}$ to $\mathrm{NaH}_{2} \mathrm{PO}_{2} \cdot \mathrm{H}_{2} \mathrm{O}$ in the synthetic process. 


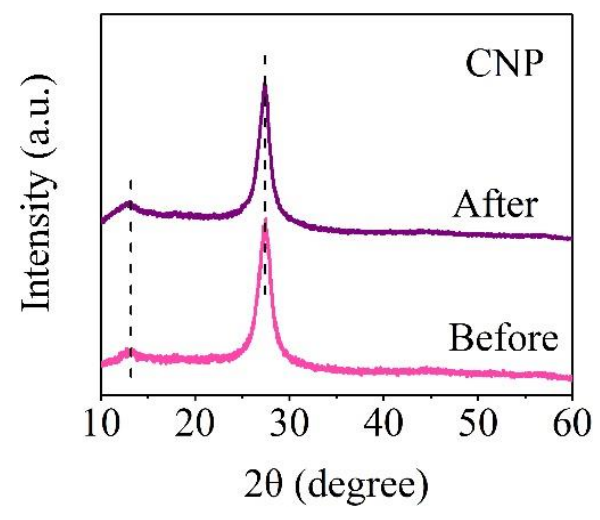

Figure S17. XRD patterns of CNP before and after cyclic photocatalytic reactions.
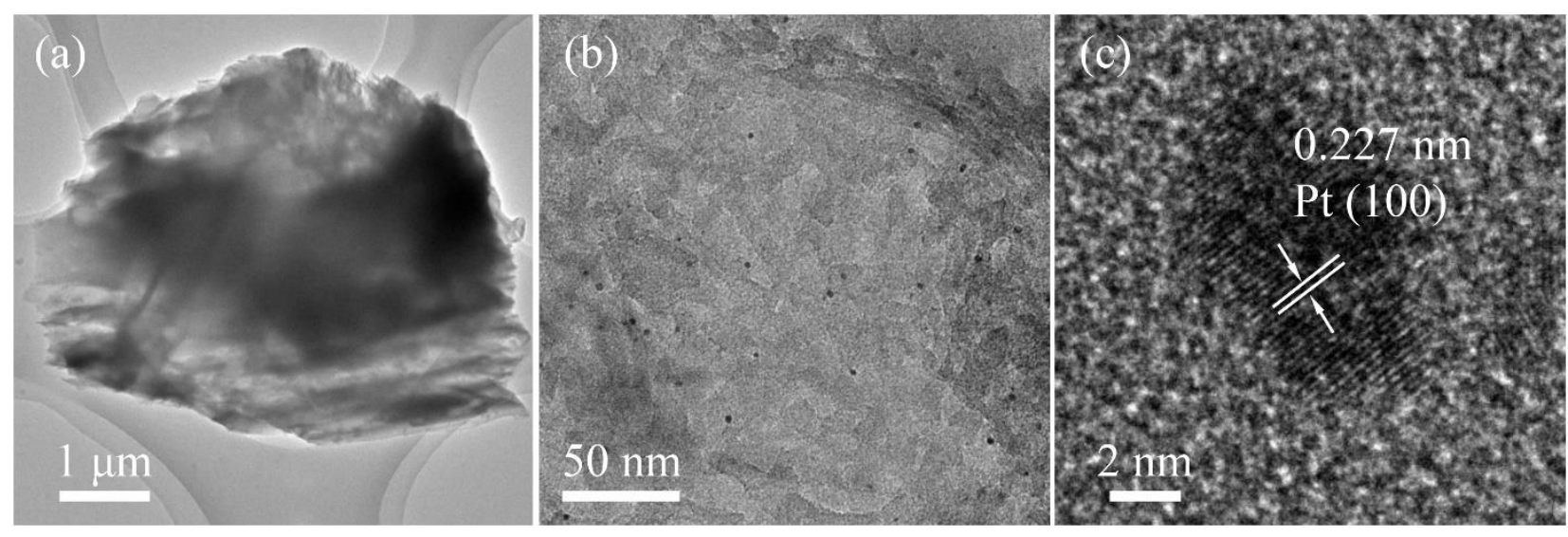

Figure S18. TEM images of CNP after cyclic photocatalytic hydrogen evolution reaction for 20

$\mathrm{h}$, the black dots in (b) and (c) show the Pt nanoparticles in situ deposited on the surface of CNP in the photocatalytic reaction. 


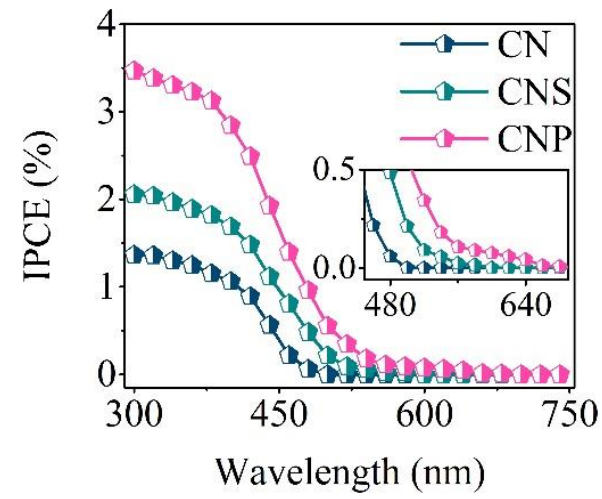

Figure S19. IPCE plots of CN, CNS and CNP. 
Table S2 A comparison in the photocatalytic hydrogen evolution performance of CNP with recent reported $\mathrm{g}-\mathrm{C}_{3} \mathrm{~N}_{4}$ based photocatalytic systems.

\begin{tabular}{|c|c|c|c|c|c|c|}
\hline Catalyst & Lamp & $\begin{array}{c}\text { HER } \\
\left(\mu \mathrm{mol} \cdot \mathrm{h}^{-}\right. \\
\left.{ }^{1} \cdot \mathrm{g}^{-1}\right)\end{array}$ & $\begin{array}{c}\mathrm{S}_{\mathrm{BET}} \\
\left(\mathrm{m}^{2} \cdot \mathrm{g}^{-1}\right)\end{array}$ & $\begin{array}{l}\text { Normalized } \\
\qquad \text { HER } \\
\left(\mu \mathrm{mol} \cdot \mathrm{h}^{-}\right. \\
\left.1 \cdot \mathrm{m}^{-2}\right)\end{array}$ & $\begin{array}{l}\mathrm{AQE} \\
(\%)\end{array}$ & Ref \\
\hline g- $\mathrm{C}_{3} \mathrm{~N}_{4}$ seaweed & $\lambda>400 \mathrm{~nm}$ & 9900 & 130 & 76.2 & - & 18 \\
\hline $\mathrm{g}-\mathrm{C}_{3} \mathrm{~N}_{4}$ nanosheet & $\begin{array}{c}\text { UV-Vis } \\
\text { light }\end{array}$ & 3410 & 306 & 11.1 & - & 19 \\
\hline Porous g- $\mathrm{C}_{3} \mathrm{~N}_{4}$ & $\lambda>400 \mathrm{~nm}$ & 1399 & 72 & 19.5 & - & 20 \\
\hline $\begin{array}{l}\text { Copolymerized g- } \\
\qquad \mathrm{C}_{3} \mathrm{~N}_{4}\end{array}$ & $\lambda>400 \mathrm{~nm}$ & 10700 & 82 & 130.5 & - & 22 \\
\hline $\begin{array}{l}\text { Copolymerized g- } \\
\qquad \mathrm{C}_{3} \mathrm{~N}_{4}\end{array}$ & $\lambda>420 \mathrm{~nm}$ & 699 & 51 & 13.7 & - & 23 \\
\hline Co-doped g- $\mathrm{C}_{3} \mathrm{~N}_{4}$ & $\lambda>400 \mathrm{~nm}$ & 560 & 33 & 17.0 & - & 29 \\
\hline O-doped g- $\mathrm{C}_{3} \mathrm{~N}_{4}$ & $\lambda>420 \mathrm{~nm}$ & 602 & 19 & 61.2 & 7.8 & 32 \\
\hline $\begin{array}{c}\text { Porous } \mathrm{g}-\mathrm{C}_{3} \mathrm{~N}_{4} \\
\text { nanorod }\end{array}$ & $\lambda>420 \mathrm{~nm}$ & 3500 & 80 & 43.8 & 3.0 & 33 \\
\hline Br-doped g- $\mathrm{C}_{3} \mathrm{~N}_{4}$ & $\lambda=400 \mathrm{~nm}$ & 960 & 54 & 17.8 & - & 35 \\
\hline Cl-doped g- $\mathrm{C}_{3} \mathrm{~N}_{4}$ & $\lambda>400 \mathrm{~nm}$ & 537 & 22 & 24.4 & 13.7 & 36 \\
\hline $\begin{array}{l}\text { Fe-P co-doped g- } \\
\qquad \mathrm{C}_{3} \mathrm{~N}_{4}\end{array}$ & $\lambda>400 \mathrm{~nm}$ & 122 & 18.2 & 6.7 & 6.9 & 38 \\
\hline $\begin{array}{l}\text { P-Na co-doped g- } \\
\qquad \mathrm{C}_{3} \mathrm{~N}_{4}\end{array}$ & $\begin{array}{c}\text { UV-Vis } \\
\text { light }\end{array}$ & 3820 & 11 & 347.3 & - & 40 \\
\hline $\begin{array}{l}\text { Thiourea-derived g- } \\
\qquad \mathrm{C}_{3} \mathrm{~N}_{4}\end{array}$ & $\lambda>420 \mathrm{~nm}$ & 3144 & 52 & 60.5 & - & 45 \\
\hline $\begin{array}{l}\text { I-O-Na co-doped g- } \\
\qquad \mathrm{C}_{3} \mathrm{~N}_{4}\end{array}$ & $\lambda>420 \mathrm{~nm}$ & 5515 & 33 & 167.1 & - & 41 \\
\hline P-doped g- $\mathrm{C}_{3} \mathrm{~N}_{4}$ & $\begin{array}{l}\text { Visible } \\
\text { light }\end{array}$ & 2080 & 273 & 7.6 & - & 46 \\
\hline P-doped g- $\mathrm{C}_{3} \mathrm{~N}_{4}$ & $\lambda>420 \mathrm{~nm}$ & 1596 & 123 & 12.9 & 3.6 & 47 \\
\hline $\begin{array}{l}\text { Copolymerized g- } \\
\qquad \mathrm{C}_{3} \mathrm{~N}_{4}\end{array}$ & $\lambda>420 \mathrm{~nm}$ & 294 & 22 & 13.4 & - & 56 \\
\hline CNP & $\lambda>400 \mathrm{~nm}$ & 2032 & 3 & 641 & 6.3 & $\begin{array}{l}\text { This } \\
\text { work }\end{array}$ \\
\hline
\end{tabular}

